\title{
Aboveground biomass estimation at different scales for subtropical forests in China
}

Shunlei Peng ${ }^{1,2^{*}}$, Nianpeng He $\mathrm{e}^{1,3}$, Guirui $\mathrm{Yu}^{1,3^{*}}$ and Qiufeng Wang ${ }^{1,3}$

\begin{abstract}
Background: The accurate estimation of forest biomass at different scales is the critical step in the assessment of forest carbon stocks. We used three models at increasing scales: allometric model at ecoregional scale (model 1), dummy variable allometric model at both ecoregion and regional scales (model 2), and allometric model at regional scale (model 3) to estimate the aboveground biomass of six subtropical forests in China. Furthermore, we also tested whether wood density can improve the accuracy of the allometric model at regional scale.

Results: Aboveground biomass estimates for six subtropical forests were significantly affected by the ecoregions ( $p<0.05$ ). Model 1 and model 2 had good fitness with higher values of $R^{2}$, lower RSE (residual standard error) and MPSE (mean percent standard error) than model 3. The values of MPSE for model 1, model 2, and model 3 ranged from 2.79 to $30.40 \%, 5.15$ to $40.94 \%$, and 13.25 to $80.81 \%$ at ecoregion scale, respectively. At regional scale, MPSE of model 2 was very similar to that of model 1 , and was less than model 3 . New allometric models with wood density had greater $R^{2}$, lower RSE and MPSE than the traditional allometric models without wood density variable for six subtropical forests at regional scale.
\end{abstract}

Conclusion: The dummy variable allometric models have better performances to estimate aboveground biomass for six subtropical forests in China, which provided an effective approach to improve the compatibility of forest biomass estimations from different scales. New allometric models with wood density substantially improved accuracies of aboveground biomass estimation for subtropical forests at regional scale.

Keywords: Aboveground biomass, Dummy variable model, Wood density, Scale, Allometric equation

\section{Background}

Carbon $(C)$ sequestration and accumulation in forests as aboveground biomass (AGB) is important for mitigating climate change. The estimation of forest biomass at a range of scales has been recognized as one of the most critical steps in the assessment of forest $C$ stocks (Montagu et al. 2005; Tomppo et al. 2010). Tropical and subtropical forests have been reported to account for more than $40 \%$ of the global gross primary production (GPP) and net primary production (NPP) (Zhou et al. 2006;

\footnotetext{
*Correspondence: pengshunlei@163.com; yugr@igsnrr.ac.cn ${ }^{1}$ Key Laboratory of Ecosystem Network Observation and Modeling, Institute of Geographic Sciences and Natural Resources Research, CAS, Beijing 100101, People's Republic of China

Full list of author information is available at the end of the article
}

Beer et al. 2010; Pan et al. 2011). Long-term eddy covariance observations demonstrate that average net ecosystem production (NEP) of East Asian subtropical forests is $362 \mathrm{~g} \mathrm{C} \mathrm{m}^{-2}$ year $^{-1}$, greater than that of Asian tropical and temperate forests, and also higher than that of forests at the same latitude in North America, Europe and Africa (Yu et al. 2014). Subtropical forest biome in China covers $2.5 \times 10^{6} \mathrm{~km}^{2}$, occupies about $25 \%$ of the total forest area in China (Wu 1995), and plays critical role in C sink and climate change regulating (Zhou et al. 2006; Tan et al. 2011; Yu et al. 2014). However, $C$ budgets of these forests remain uncertain resulted in limited number of inventory plot biomass data and accuracies of allometric equations for estimating AGB of forests in subtropical region (Zhang et al. 2005; Xu et al. 2015; Xiang et al. 2016). Thus, 
developing allometric equations for subtropical forests is essential for accurate estimating $C$ sequestration in subtropical region (Zaehle et al. 2006; Hudiburg et al. 2009).

Field inventory methods (e.g., harvest method, allomatric modeling, and biomass expansion factor methods) are often used to estimate forest biomass at local and regional scales (Brown et al. 1989; Fang et al. 2001; Wang 2006; Pajtik et al. 2008; Williams et al. 2012). Remote sensing methods can provide spatial information on AGB at large scales, but this method still linked with the relationship between remote sensing dataset and field inventory AGB dataset (Drake et al. 2003; Su et al. 2016). Thus, many scientists gave efforts to improve the tree allometric models at single tree, plot, regional, national, or even worldwide scales, using easily measured dimensional variables, such as diameter at breast high $(D B H)$ and tree height $(H)$ (Brown et al. 1989; Ter-Mikaelian and Korzukhin 1997; Chave et al. 2005; Návar 2009; Genet et al. 2011). However, different models may lead to greatly variation of biomass estimation because of difference in climatic conditions, site quality, and forest types (Muukkonen 2007; Fu et al. 2017). Therefore, sampling at different scales and creating general biomass model were very important to reduce the uncertainty of applying different models (Chave et al. 2014). Some studies have advanced the possibility of generalizing allometric equations across regional boundaries (Návar et al. 2013; Paul et al. 2013; Chave et al. 2014). Zeng et al. (2011) used dummy variable model to develop generalized biomass model of Pinus massoniana at regional scale in south China, and indicated dummy model had good performance. However, few study has compared the accuracy of these allometric equations for forest biomass estimations from site to regional scales (Návar et al. 2013). Moreover, allometric models at different scales for other main subtropical forests in china, such as evergreen broadleaf forest, deciduous broadleaf forest, and mixed forests were very lack (Xu et al. 2015; Xiang et al. 2016). Some studies indicate that wood density variable can greatly improve accuracies of biomass model for AGB estimates in tropical forests and subtropical evergreen broadleaved forest (Baker et al. 2004; Chave et al. 2005, 2014; Goodman et al. 2014; $\mathrm{Xu}$ et al. 2015). Chave et al. (2014) successfully developed the universal allometric model for tropical forests with wood density based on global database, which were widely used for AGB estimation in tropical forests. However, the performance of the allometric model with wood density was worth further testing in subtropical forests. Therefore, the development of generalized biomass allometric model at different scales was urgent to quantify the regional biomass and $C$ storage of subtropical forests.

Subtropical region in China has varied ecological zones and forest types (Chinese Academy of Sciences 2001).
It was very necessary to develop general biomass models based on ecological region to improve accuracies of AGB estimation. The main objectives of this study were (1) to develop the allometric models at different scales for aboveground biomass estimation of subtropical forests in China; (2) to assessment the accuracy of the allometric models at different scales for AGB estimates, and (3) to test the performance of the allometric model when wood density variable is available.

\section{Materials and methods}

\section{The experimental site}

The study region covered most of the subtropical regions of China $\left(22^{\circ}-34^{\circ} \mathrm{N}, 98^{\circ}-123^{\circ} \mathrm{E}\right)$ extending across eight ecoregions (Fig. 1). The total forested area is approximately $2.5 \times 10^{6} \mathrm{~km}^{2}$ in China (Wu 1995). The region was classified eight ecological zones (Table 1; Fig. 1) (Fu et al. 2013). The mean annual precipitation (MAP) ranges from 831 to $1342 \mathrm{~mm}$ and the mean annual temperature (MAT) varies from 12.5 to $19.1{ }^{\circ} \mathrm{C}$ (Table 1 ). The primary forests in this region were evergreen broadleaf forests (EBF). Due to long-term anthropogenic disturbances, the current forests were not primitive and were classified into six categories: Cunninghamia lanceolata (CL), coniferous mixed broadleaf forest (CMBF), subtropical deciduous broadleaf forest (DBF), evergreen broadleaf forest (EBF), Eucalyptus tree species forest (ETS), and Pinus massoniana (PM) based on China's vegetation classification system (Chinese Academy of Sciences 2001).

\section{The dataset}

The AGB data of the six subtropical forests (CL, CMBF, DBF, EBF, ETS, and PM) was collected from the large forest biomass dataset in China, which was compiled from published biomass studies and pre-existing datasets published between 1978 and 2008 (Luo et al. 2013).

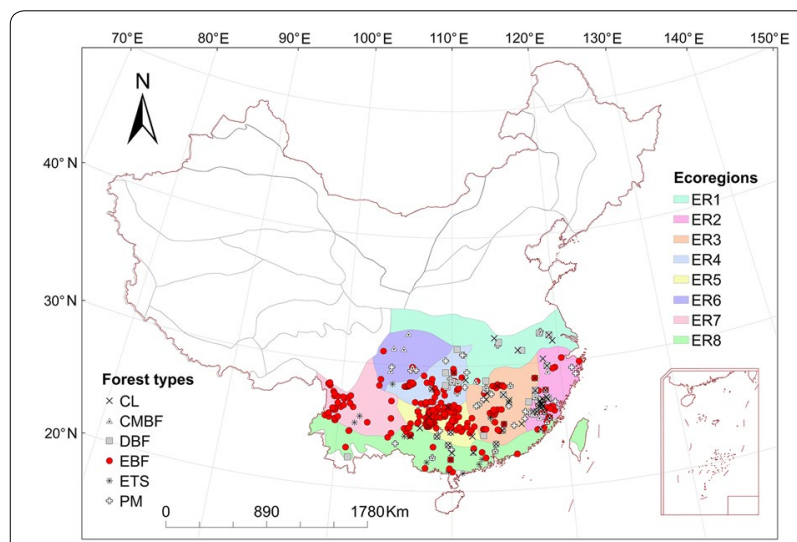

Fig. 1 The sampling plot locations for the six forest types in the subtropical region of China. See Table 1 for the abbreviations of the forest types and ecoregions 
Table 1 Summary characteristics of six forests and eight ecoregions in the subtropical region of China

\begin{tabular}{|c|c|c|c|c|c|c|c|c|}
\hline \multirow[t]{2}{*}{ Forest types } & \multirow[t]{2}{*}{$N$} & \multirow[t]{2}{*}{$n$} & \multicolumn{3}{|l|}{$\mathrm{D}^{2} \mathrm{H}$} & \multicolumn{3}{|c|}{ AGB (kg) } \\
\hline & & & Min & Max & Mean & Min & Max & Mean \\
\hline Cunninghamia lanceolata forest (CL) & 6 & 219 & 16.97 & $23,469.40$ & 2878.59 & 1.25 & 358.95 & 49.86 \\
\hline Coniferous mixed broadleaf forest (CMBF) & 6 & 77 & 20.39 & 9973.85 & 1587.48 & 1.35 & 156.32 & 42.84 \\
\hline Deciduous broadleaf forest (DBF) & 5 & 40 & 50.69 & 9481.50 & 2157.55 & 2.76 & 240.26 & 59.28 \\
\hline Evergreen broadleaf forest (EBF) & 6 & 277 & 80.69 & $42,360.52$ & 4492.07 & 3.85 & 719.51 & 121.74 \\
\hline Eucalyptus tree species forest (ETS) & 5 & 76 & 84.24 & 6149.86 & 1882.65 & 2.25 & 201.05 & 46.72 \\
\hline Pinus massoniana forest (PM) & 7 & 283 & 16.25 & $19,822.5$ & 2297.85 & 1.01 & 388.74 & 53.75 \\
\hline \multirow[t]{2}{*}{ Ecoregions } & \multirow[t]{2}{*}{$M$} & \multirow[t]{2}{*}{$n$} & \multicolumn{3}{|c|}{ MAT $\left({ }^{\circ} \mathrm{C}\right)$} & \multicolumn{3}{|c|}{ MAP (mm) } \\
\hline & & & Min & Max & Mean & Min & Max & Mean \\
\hline Yangtze river delta ecological zone (ER1) & 4 & 55 & 5.3 & 17.2 & 14.0 & 491 & 1381 & 907 \\
\hline $\begin{array}{l}\text { Evergreen broadleaf forest ecological zone in } \\
\text { the mountains of Zhejiang and Fujian prov- } \\
\text { inces (ER2) }\end{array}$ & 6 & 254 & 11.6 & 20.4 & 16.5 & 1022 & 1653 & 1342 \\
\hline $\begin{array}{l}\text { Ecological zone in Jiangnan and Nanling moun- } \\
\text { tains and hill (ER3) }\end{array}$ & 6 & 185 & 13.0 & 20.7 & 16.9 & 1069 & 1626 & 1385 \\
\hline $\begin{array}{l}\text { Evergreen broadleaf forest ecological zone in } \\
\text { the mountains of the west Hunan, Guizhou } \\
\text { and Hubei provinces (ER4) }\end{array}$ & 6 & 161 & 7.4 & 17.7 & 14.8 & 798 & 1356 & 1073 \\
\hline $\begin{array}{l}\text { Karst evergreen broadleaf forest and agricultural } \\
\text { ecological zone in Guizhou and Guangxi } \\
\text { provinces (ER5) }\end{array}$ & 3 & 121 & 10.1 & 21.1 & 16.9 & 887 & 1493 & 1254 \\
\hline Ecological zone of Sichuan Basin (ER6) & 2 & 39 & 7.3 & 18.1 & 15.4 & 677 & 1232 & 911 \\
\hline Ecological zone on Yunnan Plateau (ER7) & 2 & 36 & -8.3 & 19.6 & 12.5 & 618 & 1129 & 831 \\
\hline South humid subtropical ecological zone (ER8) & 6 & 121 & 6.9 & 22.9 & 19.1 & 833 & 1770 & 1252 \\
\hline
\end{tabular}

Abbreviations in the brackets indicated each forest type and individual ecoregion, respectively in the subtropical region of China. Climate data, including mean annual temperature (MAT) and mean annual precipitation (MAP) was obtained from the National Climate Center (http://ncc.cma.gov.cn/cn/)

$N$ number of forest distributed ecoregions, $n$ number of sampling plots, $M$ number of forest types

Moreover, we reviewed almost all related publications in China from 2008 to 2013 and recorded information of sampling plots on locations, forest types, stand age, stand density, DBH, tree height, wood density and AGB for the six subtropical forest types. The biomass components of sample trees (stems, branches, leaves, etc.) was measured using destructive harvesting and oven weighing method. Then, AGB of average tree $(\mathrm{kg})$ for each plot was calculated from stand AGB $\left(\mathrm{Mg} \mathrm{ha}^{-1}\right)$ and stand density. Our criteria for selected sampling tress was that the sample trees for each forest types were distributed as evenly as possible in the diameter classes in our dataset. Together, we collected 972 records of plot measured AGB data for the average trees of six subtropical forest types (Table 1; Additional file 1: Figure S1), 316 records of which had wood density information. The locations and forest types of the dataset were shown in Fig. 1.

\section{Model description}

\section{Allometric model at different scales}

We used general allometric equations to estimate AGB of six subtropical forests at individual ecoregional scale (model 1) and all subtropical regional scale (model 3), respectively. These allometric equations based on $D^{2} H$ ( $D$, diameter of the tree at breast height, $\mathrm{cm}$, and $H$, tree height, $\mathrm{m}$ ), which have been widely used to estimate AGB for forests (Jenkins et al. 2003; Muukkonen 2007; Návar 2009).

$$
\ln (A G B)=a+b \ln \left(D^{2} H\right)+\varepsilon
$$

where $A G B$ is the aboveground biomass, $a$ and $b$ are parameters, and $\varepsilon$ is the additive error. Then, the estimate of aboveground biomass is as follows:

$$
A G B_{\text {est }}=\exp \left(a+R S E^{2} / 2\right) \times\left(D^{2} H\right)^{b}
$$

where RSE is the residual standard errors of the regressions.

We considered ecoregion as dummy variable and used dummy variable allometric model to estimate AGB for six subtropical forests at both ecoregion scale and regional scale (model 2). The general form of the dummy variable allometric model was as follows (Wang et al. 2008; Zeng et al. 2011). 


$$
\begin{aligned}
& \ln (A G B)=a_{0}+\sum a_{i} z_{i}+b \ln \left(D^{2} H\right)+\varepsilon \\
& A G B_{\mathrm{est}}=\exp \left(a_{0}+\sum a_{i} z_{i}+R S E^{2} / 2\right) \times\left(D^{2} H\right)^{b}
\end{aligned}
$$

where $z_{i}$ is the dummy variable, $a_{i}$ is the ecoregionspecific parameter, and other symbols are the same as Eqs. (1) and (2). The dummy variables are 0, 1. In model 2 , we take each ecoregion as dummy variable, if forest has six distributed ecoregions, we used six dummy variables, $\mathrm{z}_{1}, \mathrm{z}_{2}, \mathrm{z}_{3}, \mathrm{z}_{4}, \mathrm{z}_{5}$ and $\mathrm{z}_{6}$, when $\mathrm{z}_{1}=1$, the others $=0$, when $z_{2}=1$, the others $=0$, etc. (Zeng et al. 2011).

\section{Testing the importance of wood density for accurate estimated $A G B$}

At regional scale, we used 316 plot AGB data with wood density $(W D)$ records to test whether $W D$ improved accuracy of allometric model. $D^{2} H \times W D$ as variable was used to fit allometric model compared with the model without WD variable (Chave et al. 2014; Xu et al. 2015).

$$
\ln (A G B)=a+b \ln \left(D^{2} H \times W D\right)+\varepsilon
$$

then, the estimate of biomass is as follows:

$$
A G B_{\mathrm{est}}=\exp \left(a+R S E^{2} / 2\right) \times\left(D^{2} H \times W D\right)^{b}
$$

\section{Accuracy assessment of models}

The coefficient of determination $\left(R^{2}\right)$, residual standard error of the regression (RSE), and mean percent standard error (MPSE) were used to assess the accuracies of the models (Zeng et al. 2011). MPSE were defined as follows:

$$
M P S E=\frac{1}{n} \sum\left|\left(\mathrm{y}_{i}-\hat{y}\right) / \hat{y}\right| \times 100
$$

where $n$ is number of plots; $y_{i}$ and $\hat{y}$ are the observed and estimated values of AGB respectively.

\section{Results}

\section{Allometric models for aboveground biomass estimation at different scales}

The values of $\mathrm{AGB}$ and $\mathrm{D}^{2} \mathrm{H}$ varied obviously in each forest type and each ecoregion, especially in DBF, ETS, CMBF and EBF (Table 1; Additional file 1: Figure S1). There was clear distinction of climate (e.g., MAT and MAP) among eight ecoregions (Table 1).

Model 1 had better performance for CL in ER4 $\left(R^{2}=0.987\right)$ and ER5 $\left(R^{2}=0.986\right)$, for CMBF in ER4 $\left(R^{2}=0.978\right)$ and ER6 $\left(R^{2}=0.961\right)$, for DBF in ER1 $\left(R^{2}=0.975\right)$ and ER4 $\left(R^{2}=0.961\right)$, for EBF in ER7
$\left(R^{2}=0.978\right)$ and ER4 $\left(R^{2}=0.968\right)$, for ETS in ER2 $\left(R^{2}=0.999\right)$ and ER4 $\left(R^{2}=0.979\right)$, and for PM in ER5 $\left(R^{2}=0.986\right), \operatorname{ER} 6\left(R^{2}=0.979\right), \operatorname{ER} 3\left(R^{2}=0.970\right)$ and ER2 $\left(R^{2}=0.960\right)$, and showed lower performance for CMBF in ER2 $\left(R^{2}=0.889\right)$, and for EBF in ER8 $\left(R^{2}=0.885\right)$ (Table 2; Additional file 1: Figure S2).

Model 2 considered the effects of the ecoregions on AGB estimation. The statistical results showed ER2 significantly influenced AGB estimations for CL $(p<0.05)$, and for PM $(p<0.01)$, respectively. ER8 significantly affected on AGB estimations for DBF $(p<0.001)$, EBF $(p<0.001)$, CMBF $(p<0.05)$ and ETS $(p<0.05)$. ER4, ER5, ER3, and ER8 significantly affected on AGB estimation for EBF, especially ER4 and ER5 $(p<0.0001)$ (Table 3; Additional file 1: Figure S3).

Model 2 had better performance to estimate AGB for $\operatorname{PM}\left(R^{2}=0.964\right)$, ETS $\left(R^{2}=0.954\right)$, and CL $\left(R^{2}=0.947\right)$, and showed lower performance to estimate AGB for EBF $\left(\mathrm{R}^{2}=0.915\right)$ and $\mathrm{CMBF}\left(R^{2}=0.920\right)$ (Table 3; Additional file 1: Figure S3).

Model 3 showed better performance to estimate AGB for PM $\left(R^{2}=0.959\right)$ and CL $\left(R^{2}=0.944\right)$, and had lower performance to estimate AGB for the other four forest types, especially for ETS $\left(R^{2}=0.759\right)$ (Table 4; Additional file 1: Figure S4).

\section{Assessment the accuracies of the allometric models at different scales}

We compared measured AGB and predicted AGB estimated from three allometric models at different scales, and found that model 1 and model 2 had better accuracies for AGB estimations than model 3 (Fig. 2, Table 5). The MPSE values of three models varied obviously for AGB estimations in the same forest in different ecoregions, and showed increasing trend with increasing scales. At ecoregional scale, the values of MPSE from model 2 were similar to model 1, less than model 3 for CL, PM and DBF in the distributed ecoregions except for CL and PM in ER5, and for DBF in ER3 and ER4. For EBF and ETS, MPSE showed the same trend in the ecoregions except for EBF in ER1 and ETS in ER2. For all the forests, MPSE of Model 1, model 2, and model 3 ranged from 2.79 to $30.40 \%, 5.15$ to $40.94 \%$, and 13.25 to $80.81 \%$ at ecoregional scale, respectively. At regional scale, MPSE of model 2 was very similar to model 1 , and was clearly less than model 3 in six subtropical forests (Table 5).

\section{Testing importance of wood density for Aboveground biomass estimation}

Figure 3 showed that WD variable used in allometric model greatly improved the estimate accuracies with 
Table 2 Parameters of allometric models for estimating aboveground biomass of six forests at individual ecoregion scale in the subtropical region of China

\begin{tabular}{|c|c|c|c|c|c|c|}
\hline Forests & Ecoregions & Allometric models at individual ecoregion scale (model 1 ) & $n$ & $R^{2}$ & RSE & $F$ value \\
\hline \multirow[t]{6}{*}{$\mathrm{CL}$} & ER1 & $\exp (-3.006+0.008) \times\left(D^{2} H\right)^{0.857}$ & 14 & 0.918 & 0.123 & $134.9^{* * *}$ \\
\hline & ER2 & $\exp (-2.065+0.029) \times\left(D^{2} H\right)^{0.762}$ & 92 & 0.946 & 0.241 & $1574.6^{* * *}$ \\
\hline & ER3 & $\exp (-1.431+0.034) \times\left(D^{2} H\right)^{0.669}$ & 57 & 0.925 & 0.260 & $679.1^{* * *}$ \\
\hline & ER4 & $\exp (-1.659+0.009) \times\left(D^{2} H\right)^{0.688}$ & 18 & 0.987 & 0.138 & $1203.8^{* * *}$ \\
\hline & ER5 & $\exp (-3.611+0.017) \times\left(D^{2} H\right)^{0.936}$ & 12 & 0.986 & 0.184 & $690.6^{* * *}$ \\
\hline & ER8 & $\exp (-2.067+0.033) \times\left(D^{2} H\right)^{0.749}$ & 26 & 0.954 & 0.256 & $499.8^{* * *}$ \\
\hline \multirow[t]{6}{*}{ CMBF } & ER1 & $\exp (-4.280+0.011) \times\left(D^{2} H\right)^{1.169}$ & 7 & 0.955 & 0.148 & $104.8^{* * *}$ \\
\hline & ER2 & $\exp (-1.746+0.057) \times\left(D^{2} H\right)^{0.744}$ & 34 & 0.889 & 0.338 & $255.6^{* * *}$ \\
\hline & ER3 & $\exp (-0.527+0.044) \times\left(D^{2} H\right)^{0.552}$ & 7 & 0.912 & 0.295 & $51.5^{* * *}$ \\
\hline & ER4 & $\exp (-0.615+0.001) \times\left(D^{2} H\right)^{0.590}$ & 7 & 0.978 & 0.053 & $222.3^{* * *}$ \\
\hline & ER6 & $\exp (-1.953+0.043) \times\left(D^{2} H\right)^{0.777}$ & 14 & 0.961 & 0.294 & $293.6^{* * *}$ \\
\hline & ER8 & $\exp (-1.391+0.048) \times\left(D^{2} H\right)^{0.72}$ & 8 & 0.932 & 0.102 & $82.2^{* * *}$ \\
\hline \multirow[t]{5}{*}{ DBF } & ER1 & $\exp (-2.054+0.019) \times\left(D^{2} H\right)^{0.803}$ & 11 & 0.975 & 0.195 & $305.3^{* * *}$ \\
\hline & ER2 & $\exp (-2.202+0.036) \times\left(D^{2} H\right)^{0.774}$ & 11 & 0.955 & 0.270 & $191.6^{* * *}$ \\
\hline & ER3 & $\exp (-14.935+0.106) \times\left(D^{2} H\right)^{2.623}$ & 5 & 0.904 & 0.460 & $28.2^{*}$ \\
\hline & ER4 & $\exp (-4.803+0.020) \times\left(D^{2} H\right)^{1.120}$ & 7 & 0.961 & 0.198 & $122.9^{* * *}$ \\
\hline & ER8 & $\exp (-0.841+0.034) \times\left(D^{2} H\right)^{0.722}$ & 6 & 0.908 & 0.262 & $39.3^{* *}$ \\
\hline \multirow[t]{6}{*}{ EBF } & ER2 & $\exp (-2.909+0.054) \times\left(D^{2} H\right)^{0.920}$ & 55 & 0.932 & 0.328 & $729.7^{* * *}$ \\
\hline & ER3 & $\exp (-0.482+0.022) \times\left(D^{2} H\right)^{0.592}$ & 29 & 0.901 & 0.209 & $245.2^{* * *}$ \\
\hline & ER4 & $\exp (-1.699+0.011) \times\left(D^{2} H\right)^{0.820}$ & 48 & 0.968 & 0.149 & $1372.4^{* * *}$ \\
\hline & ER5 & $\exp (-0.610+0.023) \times\left(D^{2} H\right)^{0.656}$ & 89 & 0.913 & 0.216 & $909.0^{* * *}$ \\
\hline & ER7 & $\exp (-2.067+0.004) \times\left(D^{2} H\right)^{0.817}$ & 28 & 0.978 & 0.086 & $1168.7^{* * *}$ \\
\hline & ER8 & $\exp (-2.761+0.068) \times\left(D^{2} H\right)^{0.911}$ & 28 & 0.885 & 0.368 & $200.8^{* * *}$ \\
\hline \multirow[t]{5}{*}{ ETS } & ER2 & $\exp (-1.305+0.000) \times\left(D^{2} H\right)^{0.687}$ & 9 & 0.999 & 0.017 & $5074.8^{* * *}$ \\
\hline & ER3 & $\exp (-5.646+0.029) \times\left(D^{2} H\right)^{1.245}$ & 12 & 0.900 & 0.240 & $90.0^{* * *}$ \\
\hline & ER4 & $\exp (-3.615+0.001) \times\left(D^{2} H\right)^{0.859}$ & 6 & 0.979 & 0.044 & $184.0^{* * *}$ \\
\hline & ER7 & $\exp (-1.352+0.021) \times\left(D^{2} H\right)^{0.631}$ & 8 & 0.924 & 0.204 & $73.3^{* * *}$ \\
\hline & ER8 & $\exp (-3.062+0.026) \times\left(D^{2} H\right)^{0.905}$ & 41 & 0.904 & 0.230 & $368.8^{* * *}$ \\
\hline \multirow[t]{7}{*}{ PM } & ER1 & $\exp (-2.515+0.020) \times\left(D^{2} H\right)^{0.843}$ & 23 & 0.948 & 0.201 & $379.7^{* * *}$ \\
\hline & ER2 & $\exp (-2.071+0.040) \times\left(D^{2} H\right)^{0.804}$ & 53 & 0.960 & 0.283 & $1214.7^{* * *}$ \\
\hline & ER3 & $\exp (-2.176+0.036) \times\left(D^{2} H\right)^{0.798}$ & 75 & 0.970 & 0.217 & $2374.4^{* * *}$ \\
\hline & ER4 & $\exp (-2.589+0.037) \times\left(D^{2} H\right)^{0.839}$ & 75 & 0.942 & 0.271 & $1181.8^{* * *}$ \\
\hline & ER5 & $\exp (-3.448+0.011) \times\left(D^{2} H\right)^{0.973}$ & 20 & 0.986 & 0.146 & $1301.2^{* * *}$ \\
\hline & ER6 & $\exp (-2.366+0.018) \times\left(D^{2} H\right)^{0.831}$ & 25 & 0.979 & 0.187 & $1058.0^{* * *}$ \\
\hline & ER8 & $\exp (-2.030+0.081) \times\left(D^{2} H\right)^{0.797}$ & 12 & 0.935 & 0.403 & $143.1^{* * *}$ \\
\hline
\end{tabular}

*** Indicates significant at $p<0.001$ level; ** indicates significant at $p<0.01$ level, * indicates significant at $p<0.05$ level. See Table 1 for the abbreviations of the forest types and ecoregions

higher $R^{2}$, lower RSE and MPSE than traditional allometric model without WD variable for six forests (Figs. 3, 4). The allometric model with WD variable developed by Chave et al. (2014) showed lower MPSE than traditional model for CL, DBF, EBF and PM, especially in EBF and DBF, and showed greater MPSE for AGB estimations in CL, CMBF, DBF, ETS and PM than allometric model with WD variable from our dataset (Fig. 4). In EBF, model created by Chave et al. (2014) showed similar lower MPSE to our model with WD variable (Fig. 4).

\section{Discussion}

Allometric models for aboveground biomass estimation at different scales

Many scientists gave efforts to improve the tree allometric models at single tree, plot, regional, national, or even worldwide scales (Brown et al. 1989; Chave et al. 2005; Návar 2009; Genet et al. 2011). In this study, we developed three allometric models from ecoregion to regional scales. Three allometric models using $D^{2} H$ as the predictive variable offered good fitness of AGB allometric 
Table 3 Parameters of dummy variable allometric model for estimating aboveground biomass of six forest types at both regional scale and ecoregion scale in the subtropical region of China

\begin{tabular}{|c|c|c|c|c|c|}
\hline Forests & Ecoregions & Dummy variable allometric model (model 2 ) & $R^{2}$ & RSE & $F$ value \\
\hline \multirow[t]{7}{*}{$\mathrm{CL}$} & General & $\exp (-2.064+0.166+0.142+0.083-0.009+0.071+0.031) \times\left(D^{2} H\right)^{0.739}$ & 0.947 & 0.249 & $631.5^{* * *}$ \\
\hline & ER1 & $\exp (-2.064+0.031) \times\left(D^{2} H\right)^{0.739}$ & & & \\
\hline & $\mathrm{ER} 2^{*}$ & $\exp (-2.064+0.166+0.031) \times\left(D^{2} H\right)^{0.739}$ & & & \\
\hline & ER3 & $\exp (-2.064+0.142+0.031) \times\left(D^{2} H\right)^{0.739}$ & & & \\
\hline & ER4 & $\exp (-2.064+0.083+0.031) \times\left(D^{2} H\right)^{0.739}$ & & & \\
\hline & ER5 & $\exp (-2.064-0.009+0.031) \times\left(D^{2} H\right)^{0.739}$ & & & \\
\hline & ER8 & $\exp (-2.064+0.071+0.031) \times\left(D^{2} H\right)^{0.739}$ & & & \\
\hline \multirow[t]{7}{*}{ CMBF } & General & $\exp (-1.391-0.18-0.143-0.134-0.239+0.398+0.048) \times\left(D^{2} H\right)^{0.720}$ & 0.920 & 0.311 & $134.5^{* * *}$ \\
\hline & ER1 & $\exp (-1.391+0.048) \times\left(D^{2} H\right)^{0.720}$ & & & \\
\hline & ER2 & $\exp (-1.391-0.180+0.048) \times\left(D^{2} H\right)^{0.720}$ & & & \\
\hline & ER3 & $\exp (-1.391-0.143+0.048) \times\left(D^{2} H\right)^{0.720}$ & & & \\
\hline & ER4 & $\exp (-1.391-0.134+0.048) \times\left(D^{2} H\right)^{0.720}$ & & & \\
\hline & ER6 & $\exp (-1.391-0.239+0.048) \times\left(D^{2} H\right)^{0.720}$ & & & \\
\hline & ER8* & $\exp (-1.391+0.398+0.048) \times\left(D^{2} H\right)^{0.720}$ & & & \\
\hline \multirow[t]{6}{*}{ DBF } & General & $\exp (-2.191-0.338+0.328-0.177+0.803+0.045) \times\left(D^{2} H\right)^{0.823}$ & 0.940 & 0.301 & $106.6^{* * *}$ \\
\hline & $E R 1^{*}$ & $\exp (-2.191+0.045) \times\left(D^{2} H\right)^{0.823}$ & & & \\
\hline & ER2 & $\exp (-2.191-0.338+0.045) \times\left(D^{2} H\right)^{0.823}$ & & & \\
\hline & ER3 & $\exp (-2.191+0.328+0.045) \times\left(D^{2} H\right)^{0.823}$ & & & \\
\hline & ER4 & $\exp (-2.191-0.177+0.045) \times\left(D^{2} H\right)^{0.823}$ & & & \\
\hline & $E R 8^{* * *}$ & $\exp (-2.191+0.803+0.045) \times\left(D^{2} H\right)^{0.823}$ & & & \\
\hline \multirow[t]{7}{*}{ EBF } & General & $\exp (-1.896-0.141+0.451+0.321+0.103+0.184+0.038) \times\left(D^{2} H\right)^{0.785}$ & 0.915 & 0.277 & $481.8^{* * *}$ \\
\hline & ER2 & $\exp (-1.896+0.038) \times\left(D^{2} H\right)^{0.785}$ & & & \\
\hline & $\mathrm{ER}^{*}$ & $\exp (-1.896-0.141+0.038) \times\left(D^{2} H\right)^{0.785}$ & & & \\
\hline & $\mathrm{ER} 4^{* * *}$ & $\exp (-1.896+0.451+0.038) \times\left(D^{2} H\right)^{0.785}$ & & & \\
\hline & $\mathrm{ER} 5^{* * *}$ & $\exp (-1.896+0.321+0.038) \times\left(D^{2} H\right)^{0.785}$ & & & \\
\hline & ER7 & $\exp (-1.896+0.103+0.038) \times\left(D^{2} H\right)^{0.785}$ & & & \\
\hline & ER8** & $\exp (-1.896+0.184+0.038) \times\left(D^{2} H\right)^{0.785}$ & & & \\
\hline \multirow[t]{6}{*}{ ETS } & General & $\exp (-2.495-0.015-1.918-0.221-0.232+0.028) \times\left(D^{2} H\right)^{0.859}$ & 0.954 & 0.237 & $288.5^{* * *}$ \\
\hline & ER2 & $\exp (-2.495+0.028) \times\left(D^{2} H\right)^{0.859}$ & & & \\
\hline & ER3 & $\exp (-2.495-0.015+0.028) \times\left(D^{2} H\right)^{0.859}$ & & & \\
\hline & $\mathrm{ER} 4^{* * *}$ & $\exp (-2.495-1.918+0.028) \times\left(D^{2} H\right)^{0.859}$ & & & \\
\hline & $E R 7^{*}$ & $\exp (-2.248-0.221+0.028) \times\left(D^{2} H\right)^{0.859}$ & & & \\
\hline & ER8* & $\exp (-2.248-0.232+0.028) \times\left(D^{2} H\right)^{0.859}$ & & & \\
\hline \multirow[t]{8}{*}{ PM } & General & $\exp (-2.369+0.168+0.053-0.102+0.048+0.072+0.156+0.032) \times\left(D^{2} H\right)^{0.821}$ & 0.964 & 0.252 & $1055.0^{* * *}$ \\
\hline & ER1 & $\exp (-2.369+0.032) \times\left(D^{2} H\right)^{0.821}$ & & & \\
\hline & $\mathrm{ER} 2 * *$ & $\exp (-2.369+0.168+0.032) \times\left(D^{2} H\right)^{0.821}$ & & & \\
\hline & ER3 & $\exp (-2.369+0.053+0.032) \times\left(D^{2} H\right)^{0.821}$ & & & \\
\hline & ER4 & $\exp (-2.369-0.102+0.032) \times\left(D^{2} H\right)^{0.821}$ & & & \\
\hline & ER5 & $\exp (-2.369+0.048+0.032) \times\left(D^{2} H\right)^{0.821}$ & & & \\
\hline & ER6 & $\exp (-2.369+0.072+0.032) \times\left(D^{2} H\right)^{0.821}$ & & & \\
\hline & ER8 & $\exp (-2.369+0.156+0.032) \times\left(D^{2} H\right)^{0.821}$ & & & \\
\hline
\end{tabular}

*** Indicates significant at $p<0.001$ level; ** indicates significant at $p<0.01$ level; * indicates significant at $p<0.05$ level. See Table 1 for the abbreviations of the forest types and ecoregions 
Table 4 Parameters of allometric models for estimating aboveground biomass of six forests at regional ecoregion scale in the subtropical region of China

\begin{tabular}{|c|c|c|c|c|c|}
\hline Forests & Allometric model at regional scale (model 3 ) & $n$ & $R^{2}$ & RSE & $F$ value \\
\hline $\mathrm{CL}$ & $\exp (-1.920+0.032) \times\left(D^{2} H\right)^{0.736}$ & 219 & 0.944 & 0.252 & $3668.5^{* * *}$ \\
\hline CMBF & $\exp (-1.485+0.062) \times\left(D^{2} H\right)^{0.718}$ & 77 & 0.890 & 0.353 & $607.4^{* * *}$ \\
\hline DBF & $\exp (-1.536+0.110) \times\left(D^{2} H\right)^{0.733}$ & 40 & 0.839 & 0.466 & $198.3^{* * *}$ \\
\hline EBF & $\exp (-1.481+0.056) \times\left(D^{2} H\right)^{0.757}$ & 277 & 0.874 & 0.334 & $1905.5^{* * *}$ \\
\hline ETS & $\exp (-3.776+0.138) \times\left(D^{2} H\right)^{0.995}$ & 76 & 0.759 & 0.526 & $233.4^{* * *}$ \\
\hline PM & $\exp (-2.394+0.036) \times\left(D^{2} H\right)^{0.830}$ & 283 & 0.959 & 0.267 & $6547.2^{* * *}$ \\
\hline
\end{tabular}

*** Indicates significant at $p<0.001$ level. See Table 1 for the abbreviations of the forest types

models at different scales ( $R^{2}$ ranged from 0.759 to 0.999$)$ (Tables $2,3,4)$. This indicates $D^{2} H$ as variable could improve accuracy of models (Muukkonen 2007; Návar 2009; Xu et al. 2015). Muukkonen (2007) found that allometric equations with only $\mathrm{DBH}$ as an independent variable provided lower overall estimations of tree biomass. Models at different scales may lead to variation of biomass estimation because of difference of climatic conditions, site quality, and forest structures (Muukkonen 2007; Fu et al. 2017). In this study, we found that model 1 and model 2 had better accuracies for AGB estimations than model 3 (Fig. 2; Table 3). The MPSE values of three models varied obviously for AGB estimations in the same forest in different ecoregions, and showed increasing trend with increasing scales. Case and Hall (2008) found that prediction error of generalized tree biomass equations for ten species in the boreal forest region of westcentral Canada increased from regional to national scale. However, MPSE of model 2 was very similar to model 1, and obviously less than model 3 in six forests (Table 5), which indicated that dummy variable allometric model considered ecoregion factors could be proposed as general model to estimate AGB for subtropical forests, and provide a more effective new approach to improve the
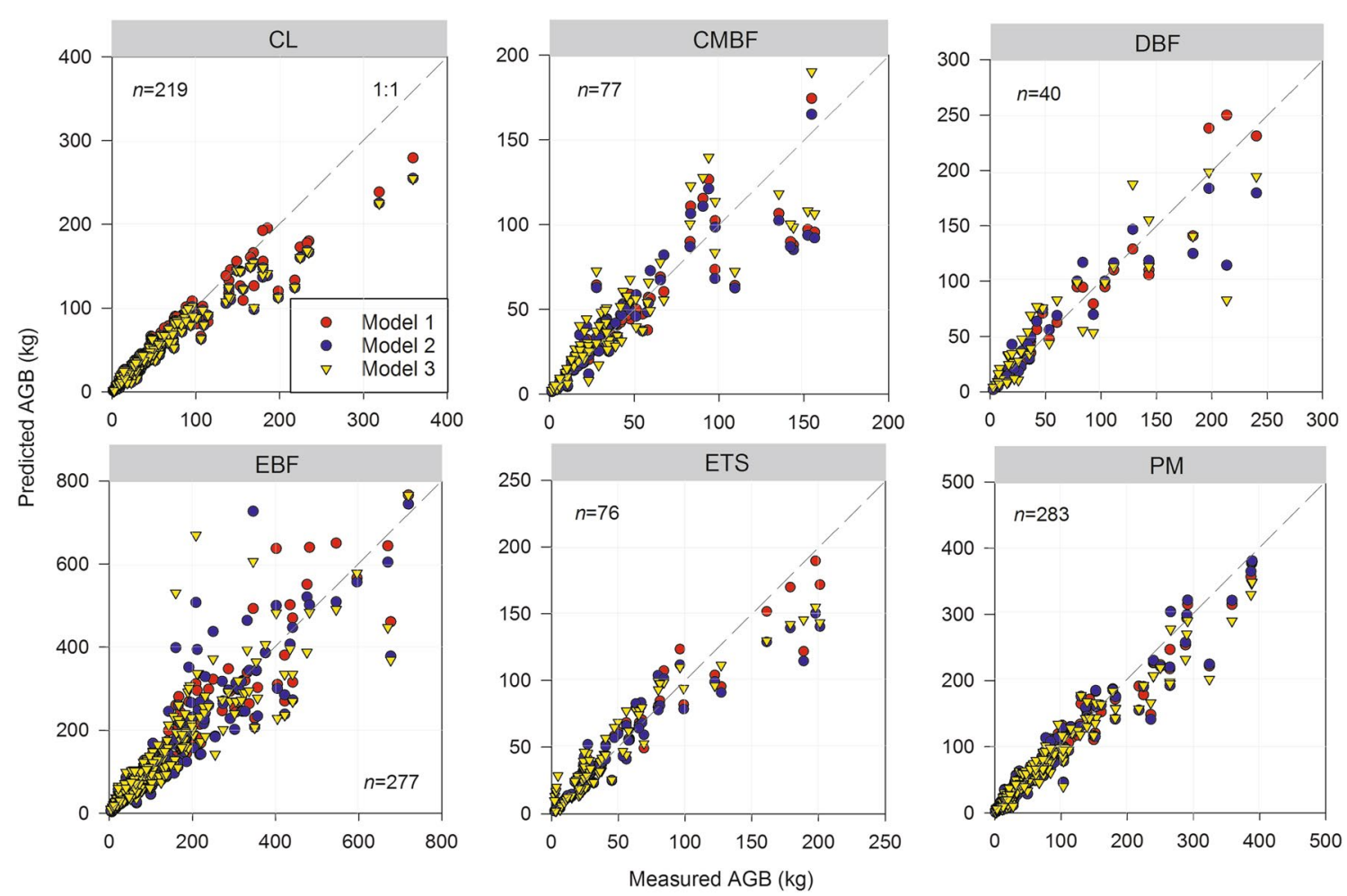

Fig. 2 Comparison measured AGB (aboveground tree biomass) and predicted AGB for six subtropical forests from three allometric models at different scales (model 1, model 2 and model 3) in China. Model 1: allometric model at ecoregion scale, model 2: dummy variable allometric model at both ecoregion scale and regional scale, and model 3: allometric model at regional scale. See Table 1 for the abbreviations of the six forest types 
Table 5 MPSE for three allometric models at different scales developed in the subtropical region of China

\begin{tabular}{|c|c|c|c|c|c|c|c|c|c|c|}
\hline \multirow[t]{2}{*}{ Forests } & \multirow[t]{2}{*}{ Models } & \multicolumn{9}{|c|}{ MPSE (\%) } \\
\hline & & ER1 & ER2 & ER3 & ER4 & ER5 & ER6 & ER7 & ER8 & Region \\
\hline \multirow[t]{3}{*}{$\mathrm{CL}$} & Model 1 & 9.51 & 19.38 & 20.26 & 10.06 & 11.72 & & & 20.41 & 17.92 \\
\hline & Model 2 & 10.83 & 19.27 & 21.49 & 11.71 & 29.08 & & & 21.07 & 19.44 \\
\hline & Model 3 & 26.04 & 21.66 & 23.99 & 21.99 & 27.36 & & & 24.02 & 23.01 \\
\hline \multirow[t]{3}{*}{ CMBF } & Model 1 & 9.66 & 26.40 & 17.89 & 3.64 & & 22.08 & & 7.75 & 19.31 \\
\hline & Model 2 & 20.97 & 26.16 & 30.69 & 7.45 & & 25.55 & & 23.19 & 23.98 \\
\hline & Model 3 & 20.68 & 28.28 & 28.79 & 13.25 & & 31.29 & & 53.38 & 29.42 \\
\hline \multirow[t]{3}{*}{ DBF } & Model 1 & 12.95 & 21.70 & 14.00 & 12.89 & & & & 14.61 & 15.73 \\
\hline & Model 2 & 12.53 & 23.90 & 40.94 & 25.35 & & & & 17.67 & 22.22 \\
\hline & Model 3 & 18.46 & 37.84 & 60.54 & 29.13 & & & & 72.78 & 39.07 \\
\hline \multirow[t]{3}{*}{ EBF } & Model 1 & & 25.24 & 13.26 & 9.82 & 16.41 & & 5.61 & 30.40 & 17.02 \\
\hline & Model 2 & & 30.74 & 17.25 & 9.87 & 18.32 & & 5.29 & 30.65 & 19.14 \\
\hline & Model 3 & & 32.27 & 29.85 & 24.61 & 21.70 & & 11.01 & 31.03 & 25.02 \\
\hline \multirow[t]{3}{*}{ ETS } & Model 1 & & 0.97 & 18.77 & 2.79 & & & 16.48 & 17.65 & 14.38 \\
\hline & Model 2 & & 8.20 & 26.37 & 5.15 & & & 20.46 & 17.54 & 16.96 \\
\hline & Model 3 & & 29.45 & 23.77 & 80.81 & & & 39.21 & 20.15 & 28.28 \\
\hline \multirow[t]{3}{*}{ PM } & Model 1 & 14.45 & 18.94 & 15.85 & 20.86 & 11.92 & 15.32 & & 27.19 & 17.80 \\
\hline & Model 2 & 14.63 & 19.73 & 16.05 & 20.75 & 19.16 & 15.39 & & 28.35 & 18.55 \\
\hline & Model 3 & 15.18 & 24.97 & 16.59 & 23.05 & 18.40 & 15.38 & & 33.35 & 20.49 \\
\hline
\end{tabular}

See Table 1 for the abbreviations of six forests and eight ecoregions

compatibility of forest biomass estimates at the ecoregional, and regional scales.

\section{Assessment the accuracies of the allometric models at different scales}

Regional climate data affected the precision of the regional model (Drake et al. 2003; Dewalt and Chave 2004; Chave et al. 2005; Wang 2006; Fu et al. 2017). In this study, MAT and MAP were clearly distinct among eight ecoregions (Table 1). Ecoregions including ER2, ER3, ER4, ER5, and ER8 significantly affected AGB estimations (Table 3). The aboveground biomass of PM, CL, and ETS was greater in the southern central regions with higher temperature and greater rainfall, than in the west regions with lower temperatures and less rainfall. The influences of climate were even more significant in EBF (Table 3). Therefore, forest regional climate data should be considered when the regional models were employed (Muukkonen 2007; Fu et al. 2017).

The number of plots applied to develop the allometric equations in ETS, DBF, and CBMF forest types $(N<100)$ may not be enough to represent the full range of species present at the study areas (Table 1). Návar (2009) reported that several hundred sampling plots were needed for fitting regional allometric equations. Moreover, three model at different scales that have been developed were more robust when there were not enough trees with diameters between 25 and $40 \mathrm{~cm}$ (Additional file 1: Figure S1), and the majority of samples had insufficient trees with a diameter of more than $25 \mathrm{~cm}$, which would lead larger estimated error of AGB (Wang 2006; Zaehle et al. 2006; Hudiburg et al. 2009; Xiang et al. 2016).

\section{Testing importance of wood density for aboveground biomass estimation}

Wood density strongly varies among different geographical regions, climate gradients, and correlated to forest structure, tree architecture (Baker et al. 2004; Chave et al. 2005, 2014). Thus, wood density can improve the performance of allometric model. In this study, we compared the performance of the allometric model with wood density variable with traditional model without wood density variable at regional scale, and the model created by Chave et al. (2014), and found the model with wood density variable had better performance than other two models (Figs. 3, 4). It indicated that taking wood density as variables in the allometric model could greatly improve accuracy of biomass model (Chave et al. 2014; Xu et al. 2015). The 

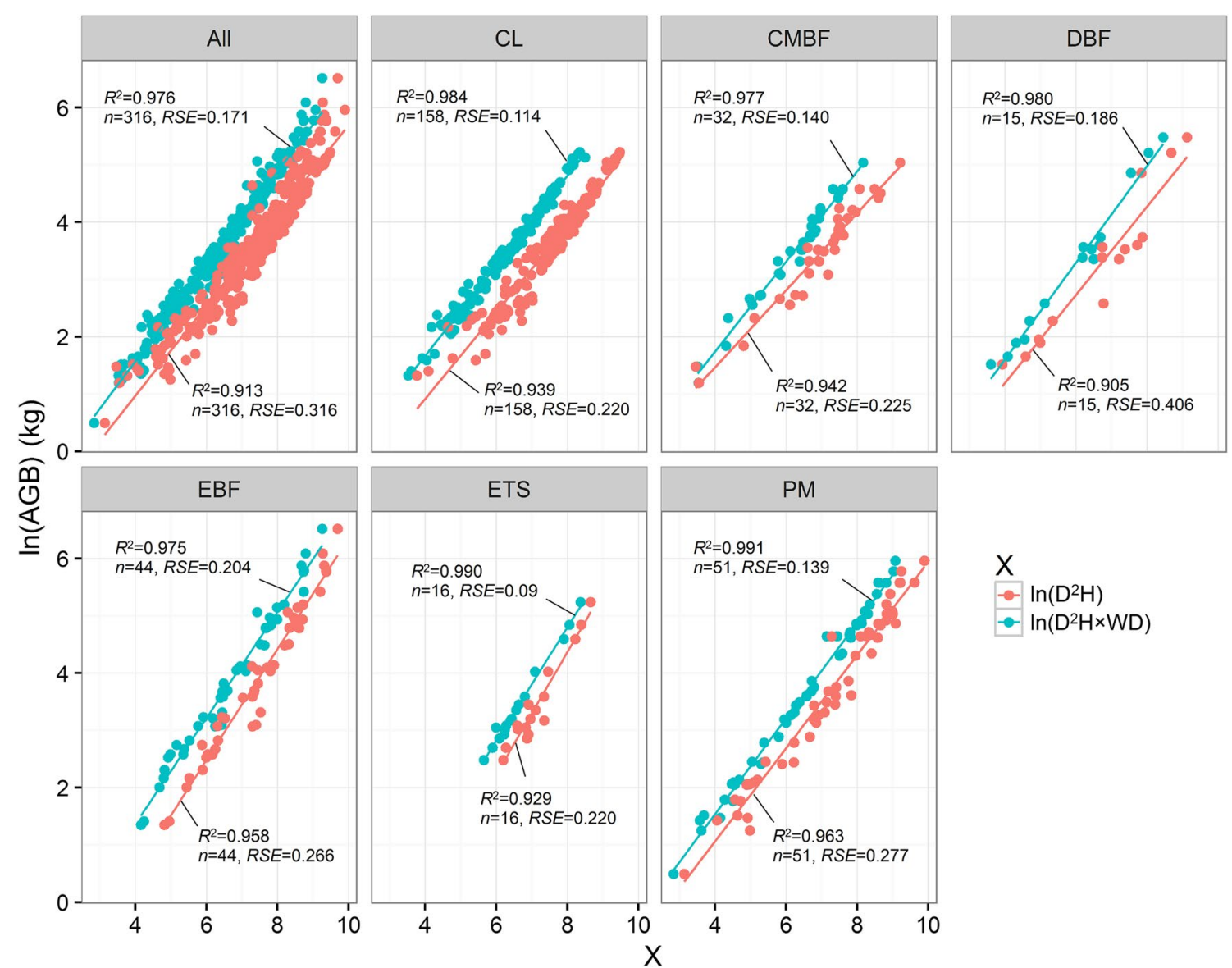

Fig. 3 Fitted curves for each forest type and all forest types at regional scale in subtropical region of China applied the allometric model with wood density variable, and the allometric model without wood density variable. See Table 1 for the abbreviations of the six forest types

reason was that wood density could reflect site climate, forest structure, and trees architecture, and reduce the effects of site climate and forest structure on AGB estimations. The model created by Chave et al. (2014) showed better performance for AGB estimation of EBF, similar to our model with wood density variable. This result suggests that the model created by Chave et al. (2014) can be used AGB estimation of EBF in subtropical region of China.

\section{Conclusions}

This study showed that ecoregions significantly affected AGB estimation for six subtropical forests in China. Dummy variable allometric model considered ecoregion as dummy variable had better performance similar to allometric model at both individual ecoregional scale and regional scale. Furthermore, we tested the performance of allometric model with wood density at regional scale and found wood density as an important variable in the allometric models greatly improved the accuracies of AGB estimations in six subtropical forests. Our findings showed that dummy variable allometric model considered ecoregion factors could be proposed as general model to estimate AGB for subtropical forests, and provide a more effective new approach to improve the compatibility of forest biomass estimates at the ecoregional, and regional scales. Moreover, the new allometric models with wood density, diameter, and tree height 

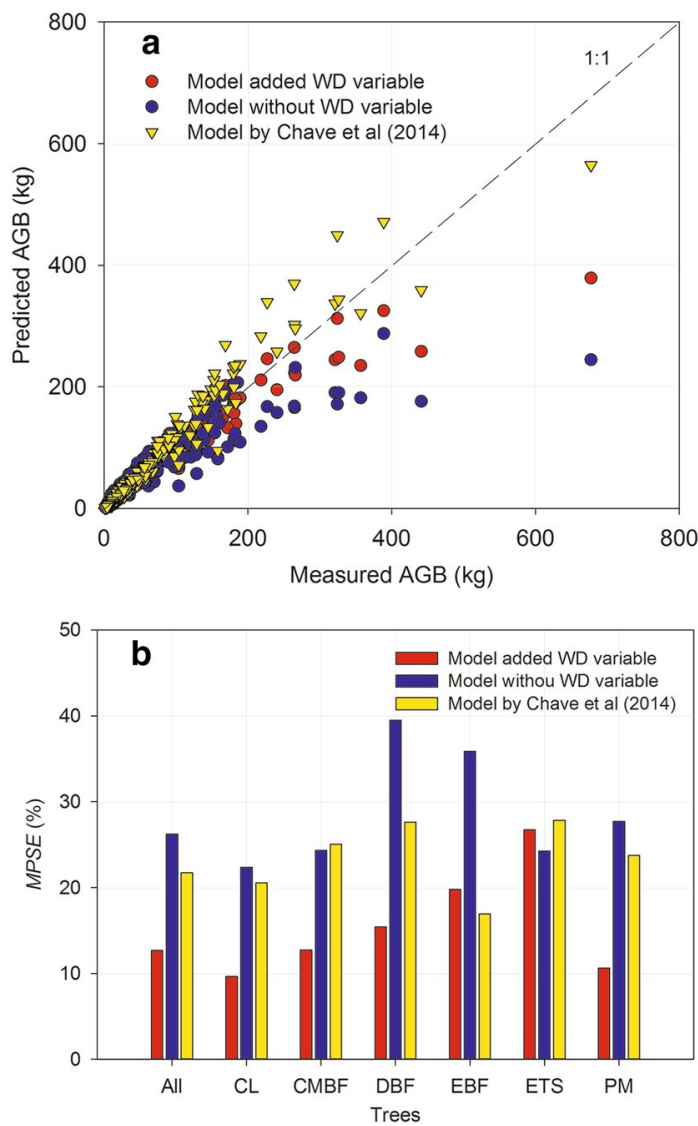

Fig. 4 Compared the measured AGB (aboveground tree biomass) and the estimated AGB in subtropical forests by the allometric model with wood density, the allometric model without wood density, and the model widely used in tropical trees created by Chave et al. (2014) $\left(\right.$ AGB $\left._{\text {est }}=0.0673 \times\left(\rho D^{2} H\right)^{0.976}\right)$, respectively $(\mathbf{a})$, and compared MPSE among these three allometric models (b)

were more accurate than the traditional models without wood density in AGB estimations for subtropical forests at regional scales.

\section{Additional file}

Additional file 1: Figure S1. Observed AGB (aboveground biomass) plotted with $D^{2} H(D$, diameter at tree breast height, $H$, tree height) of six forests distributed in eight ecoregions of subtropical region in China. Figure S2. Fitted curves for six forests applied allometric model at each ecoregion scale (model 1) in the subtropical region of China. Figure S3. Fitted curves for six forests applied dummy variable allometric model at both regional scale and ecoregion scale (model 2) in the subtropical region of China. Figure S4. Fitted curves for six subtropical forests applied allometric model at regional scale (model 3 ) in China.

\section{Authors' contributions}

All authors contributed substantially to the work reported here. The four authors participated in the design of the study. SP and NH analyzed the data and wrote the manuscript. GY wrote and reviewed the manuscript. QW performed the data collection and reviewed the manuscript. All authors read and approved the final manuscript.

\section{Author details}

${ }^{1}$ Key Laboratory of Ecosystem Network Observation and Modeling, Institute of Geographic Sciences and Natural Resources Research, CAS, Beijing 100101, People's Republic of China. ${ }^{2}$ Key Laboratory of Ecological Restoration in the Hilly Area, Pingdingshan University, Pingdingshan 467000, Henan, People's Republic of China. ${ }^{3}$ College of Resources and Environment, University of Chinese Academy of Sciences, Beijing 100049, People's Republic of China.

\section{Acknowledgements}

We thank Professor Zeng Weisheng for the assistance with information on the dummy variable model, and thank Professor Martin Kent (Plymouth University, UK) for the improvement of English usage. We also greatly thank two anonymous reviewers for their insightful comments.

\section{Competing interests}

The authors declare that they have no competing interests.

\section{Availability of data and materials}

Please see Table 1.

\section{Consent for publication}

Authors agree to the terms of the Springer Open Copyright and License Agreement.

\section{Ethics approval and consent to participate}

Not applicable, the study involves no human parparticipants.

\section{Funding}

This study is partially supported by the National Natural Science Foundation of China (No. 31770655, 31570471, 31290221).

\section{Publisher's Note}

Springer Nature remains neutral with regard to jurisdictional claims in published maps and institutional affiliations.

Received: 3 September 2016 Accepted: 26 October 2017

Published online: 09 November 2017

\section{References}

Baker TR, Phillips OL, Malhi Y et al (2004) Variation in wood density determines spatial patterns in Amazonian forest biomass. Glob Change Biol 10:545-562

Beer C, Reichstein M, Tomelleri E et al (2010) Terrestrial gross carbon dioxide uptake: global distribution and covariation with climate. Science 329:834-838

Brown S, Gillespie AJ, Lugo AE (1989) Biomass estimation methods for tropical forests with applications to forest inventory data. For Sci 35:881-902

Case B, Hall RJ (2008) Assessing prediction errors of generalized tree biomass and volume equations for the boreal forest region of west-central Canada. Canada J For Res 38:878-889

Chave J, Andalo C, Brown S et al (2005) Tree allometry and improved estimation of carbon stocks and balance in tropical forests. Oecologia 145:87-99

Chave J, Rejou-Mechain M, Burquez A et al (2014) Improved allometric models to estimate the aboveground biomass of tropical trees. Glob Change Biol 20:3177-3190

Chinese Academy of Sciences (2001) Vegetation of China and geographic pattern-illustrition for vegetation map of the People's Republic of China (1:1000000). Geological Publishing House, Beijing

Dewalt SJ, Chave J (2004) Structure and biomass of four lowland neotropical forests. Biotropica 36:7-19

Drake JB, Knox RG, Dubayah RO et al (2003) Above-ground biomass estimation in closed canopy Neotropical forest using lidar remote sensing: 
factors affecting the generality of relationships. Glob Ecol Biogeogr 12:147-159

Fang JY, Chen AP, Peng CH et al (2001) Changes in forest biomass carbon storage in China between 1949 and 1998. Science 292:2320-2322

Fu BJ, Liu GH, Ouyang ZY et al (2013) Study on ecological regionalization in China. Science Press, Beijing

Fu LY, Lei XD, Hu HD et al (2017) Integrating regional climate change into allometric equations for estimating tree aboveground biomass of Masson pine in China. Ann For Sci 74:42-57

Genet A, Wernsdörfer H, Jonard M et al (2011) Ontogeny partly explains the apparent heterogeneity of published biomass equations for Fagus sylvatica in central Europe. For Eco Manag 261:1 188-1202

Goodman RC, Phillips OL, Baker TR (2014) The importance of crown dimensions to improve tropical tree biomass estimates. Ecol Appl 24:680-698

Hudiburg T, Law B, Turner DP et al (2009) Carbon dynamics of Oregon and Northern California forests and potential land-based carbon storage. Ecol Appl 19:163-180

Jenkins JC, Chojnacky DC, Heath LS et al (2003) National- scale biomass estimators for United States tree species. For Sci 49:12-35

Luo YJ, Wang XK, Zhang XQ et al (2013) Biomass and its allocation of forest ecosystem in China. Chinese Forestry Press, Beijing

Montagu KD, Duttmer K, Barton CVM et al (2005) Developing general allometric relationship for regional estimates of carbon sequestration-an example using Eucalyptus pilularis from seven contrasting sites. For Ecol Manag 204:113-127

Muukkonen P (2007) Generalized allometric volume and biomass equations for some tree species in Europe. Eur J For Res 126:157-166

Návar J (2009) Allometric equations for tree species and carbon stocks for forests of northwestern Mexico. For Ecol Manag 257:427-434

Návar J, Ríos-Saucedo J, Pérez-Verdín G et al (2013) Regional aboveground biomass equations for North American arid and semi-arid forests. J Arid Environ 97:127-135

Pajtik J, Konopka B, Lukac M (2008) Biomass functions and expansion factors in young Norway spruce (Picea abies) trees. For Ecol Manag 256:1096-1103

Pan YD, Birdsey RA, Fang JY et al (2011) A large and persistent carbon sink in the world's forests. Science 333:988-993

Paul Kl, Roxburgh SH, Jacquel RE et al (2013) Development and testing of allometric equations for estimating above-ground biomass of mixed-species environmental plantings. For Ecol Manag 10:483-494

Su YJ, Guo QH, Xue BL et al (2016) Spatial distribution of forest aboveground biomass in China: estimation through combination of spaceborne lidar, optical imagery, and forest inventory data. Remote Sens Environ 173:187-199
Tan ZH, Zhang YP, Douglas S et al (2011) An old-growth subtropical Asian evergreen forest as a large carbon sink. Atmos Environ 45:1548-1554

Ter-Mikaelian MT, Korzukhin MD (1997) Biomass equations for sixty-five North American tree species. For Ecol Manag 97:1-24

Tomppo E, Gschwantner T, Lawrence M et al (2010) National forest inventories: pathways for common reporting. Springer Press, New York

Wang CK (2006) Biomass allometric equations for 10 co-occurring tree species in Chinese temperate forests. For Ecol Manag 222:9-16

Wang ML, Bruce EB, Zhao DH (2008) An empirical comparison of two subjectspecific approaches to dominant heights modeling: the dummy variable method and the mixed model method. For Ecol Manag 255:2659-2669

Williams RJ, Zerihum A, Montagu KD et al (2012) Allometry for estimating aboveground tree biomass in tropical and subtropical eucalypt woodlands: towards general predictive equations. Aust J Bot 53:607-619

Wu ZY (1995) Vegetation of China. Science Press, Beijing

Xiang WH, Zhou J, Ouyang S et al (2016) Species-specific and general allometric equations for estimating tree biomass components of subtropical forests in southern China. Eur J For Res 135:1-17

Xu YZ, Zhang JX, Franklin SB et al (2015) Improving allometry models to estimate the above and belowground biomass of subtropical forest, China. Ecosphere 6:1-15

Yu GR, Chen Z, Piao SL et al (2014) High carbon dioxide uptake by subtropical forest ecosystems in the East Asian monsoon region. Pro Natl Acad Sci 111:4910-4915

Zaehle S, Sitch S, Prentice C et al (2006) The importance of age-related decline in forest NPP for modeling regional carbon balances. Ecol Appl 16:1555-1574

Zeng WS, Zhang HR, Tang SZ (2011) Using the dummy variable model approach to construct compatible single-tree biomass equations at different scales- a case study for Masson pine (Pinus massoniana) in southern China. Can J For Res 41:1547-1554

Zhang L, Huang Y, Luo TX et al (2005) Age effects on stand biomass allocation to different components: a case study in forests of Cunninghamia lanceolata and Pinus massoniana. J Grad Sch Chin Acad Sci 22:170-178

Zhou GY, Liu SG, Li ZA et al (2006) Old-growth forests can accumulate carbon in soils. Science 314:1417

\section{Submit your manuscript to a SpringerOpen ${ }^{\odot}$ journal and benefit from:}

- Convenient online submission

- Rigorous peer review

- Open access: articles freely available online

- High visibility within the field

- Retaining the copyright to your article

Submit your next manuscript at $\boldsymbol{\nabla}$ springeropen.com 